\title{
EXTERNAL MASS TRANSFER MODEL FOR DEGRADATION OF SIMULATED TEXTILE EFFLUENT IN PACKED BED REACTOR
}

\author{
S. Rengadurai ${ }^{1, \otimes}$, \\ B. Preetha ${ }^{1}$, A. Ashok Kumar ${ }^{2}$, K. Manikandan ${ }^{1}$ \\ and P. Elavarasan ${ }^{1}$ \\ ${ }^{1}$ Department of Chemical Engineering, Annamalai University, Annamalai nagar - 608002, \\ Tamil nadu, India \\ ${ }^{2}$ Department of Biotechnology, Periyar Maniammai Institute of Science and Technology, \\ Vallam - 613403, Tamil nadu, India \\ Corresponding Author: sr08707@annamalaiuniversity.ac.in
}

\begin{abstract}
The present study includes the treatment of Simulated Textile Effluent (STE) with a white rot fungus Trametes hirsuta immobilized on Na-alginate mixtures, in a co-current upflow packed bed reactor. The mass transfer coefficients were calculated based on the findings of the present investigation on the degradation of STE. For STE degraded with Trametes hirsuta immobilized Na-alginate of different sizes of beads $(0.2 \mathrm{~cm}, 0.5 \mathrm{~cm}$ and $0.8 \mathrm{~cm})$, different concentration of $\operatorname{STE}(775,1550,2325$ and $3100 \mathrm{mg} / \mathrm{l}$ of COD) and different flow rates $\left(0.026,0.057,0,102,0.204\right.$ and $\left.0.408 \mathrm{~cm}^{3} / \mathrm{s}\right)$ were studied. A mass transfer model of the form $j_{D}=\mathrm{K}\left(\operatorname{Re}^{\prime}\right)^{\mathrm{n}-1} \mathrm{was}$ produced with values of ' $\mathrm{K}$ ' as $1.98,1.35$ and 1.22 , the value of ' $(\mathrm{n}-1)$ ' was found to be -0.28 .
\end{abstract}

Keywords: T.hirsuta, CR, RR251, RR111, COD, STE, Degradation.

RASĀYAN J. Chem., Vol. 14, No.1, 2021

\section{INTRODUCTION}

Around 200,000 tons of dyes are discharged along with effluents each year. Dyes are versatile chemicals, among various dyes produced. Azo dyes considered the most extensive applications. ${ }^{1}$ Azo dyes are classified based on their composition and applications. Reactive dyes are the one which is mostly used in textile industry, they are colored compounds that contain one or two functional groups able to form covalent bonds in fibre with active sites. Around $80-95 \%$ of reactive dyes having azo functional group as chromogen. ${ }^{2}$ Available data estimates that $75 \%$ of the dyes discharged from textile processing units are, reactive $(\sim 36 \%)$, acid $(\sim 25 \%)$ and direct dyes $(\sim 15 \%){ }^{3}$ Because of their colour, toxic and carcinogenic nature release of these dyes as effluents to the water bodies are undesirable without suitable treatment. Carcinogens found in the dyes predominantly benzidine, naphthalene and other aromatic compounds with heteroatoms. ${ }^{4,5}$ The elimination of these substances from the dyeing industry discharge water not only from a health point of view, but also in order to comply with government requirements. ${ }^{6}$ Current dye decolorization technologies is ineffective due to complex and varied chemical structure, dyes have higher organic content with lower BOD/COD ratios, because of these properties dyes are not easily degradable and also the degradation products are toxic. So the microbial decolorization and degradation gives the good result for dye containing effluents. Due to its low cost and relative ease of technological development, microbial dye detoxification is promising. Nevertheless, azo compounds are susceptible to form more hazardous products such as aromatic amines after being reduced or decolorized by bacterial azoreductases. ${ }^{7}$ The role and potential use of white rot fungi and their enzymes in the degradation and detoxification of dyes has been well reported and recognized. ${ }^{8}$ White rot-fungi are the most commonly used of these. Their non-specific lignin-degrading systems consisting mainly of laccases and peroxidases such as Mn-peroxidase (MnP) and Lignin-peroxidase (LiP) degrade dyes by oxidation. ${ }^{9,10}$ The relative contribution of various enzymes to decolorization in fungal cultures is not yet fully understood. ${ }^{11}$ Because the enzymatic system secreted by basidiomycetes depends even on the conditions of strain and culture, there is a need to screen more white-red fungi for their ability to degrade colors. ${ }^{12}$ Packed bed reactor gives good result for the treatment of dye containing effluents to other continuous reactors such as fluidized bed reactors, inverse fluidized bed reactors, continuous stirred tank reactors and rotating biological reactors, etc. and batch reactors. ${ }^{13,14}$ The advantages of co-current gas- liquid 
upflow packed bed reactors are high liquid residence times and high volumetric gas-liquid mass transfer coefficients. ${ }^{15,16}$ However, evidence of external film effects leading to convective mass transfer impacts the rate of degradation in immobilized packed bed reactors. ${ }^{17}$ The objective of the current study was to investigate the external mass transfer effects on biodegradation of STE using $\mathrm{Na}$ alginate beads immobilized by White rot fungs Trametes hirsuta (MTCC136) in packed bed bioreactor.

\section{Microorganism and Growth}

\section{EXPERIMENITAL}

A pure strain of Trametes hirsuta (MTCC-136), white-rot fungi in lyophilized form is procured from Institute of Microbial Type Culture Collection Centre (MTCCC), Chandigarh, India. The fungal culture was grown on nutrient agar slant medium containing yeast extract, glucose and agar. Decolorization experiments are carried out in laccase production medium containing wheat bran flakes $4.5 \mathrm{~g} / 1$, glucose $1 \mathrm{~g} / 1$, ammonium chloride $0.25 \mathrm{~g} / 1$, thiamine dichloride $0.05 \mathrm{~g} / 1$, potassium hydrogen phosphate $0.2 \mathrm{~g} / \mathrm{l}$, magnesium sulphate $0.05 \mathrm{~g} / \mathrm{l}$, calcium chloride $0.01 \mathrm{~g} / 1$, potassium chloride $0.05 \mathrm{~g} / 1 .{ }^{18}$

\section{Preparation of Immobilized Cells}

Trametes hirsuta suspension is transferred aseptically to a sterile centrifuge tube and centrifuged at $10,000 \mathrm{rpm}$ for $10 \mathrm{~min}$ and the cells are suspended in 4\% sodium alginate solution. The slurry is extruded as drops into $2 \%$ calcium chloride solution at room temperature in aseptic condition. The insoluble and stable immobilized alginate beads thus formed are hardened in the calcium chloride solution for $1 \mathrm{~h}$ at room temperature and further used for the decolorization studies. The size of the beads can be varied by changing the diameter of the syringe. Plain beads are prepared without the spore suspension and these are used as the reference beads. Figure-1 shows the visual images of the immobilized $T$. hirsuta beads before and after degradation of simulated textile wastewater.
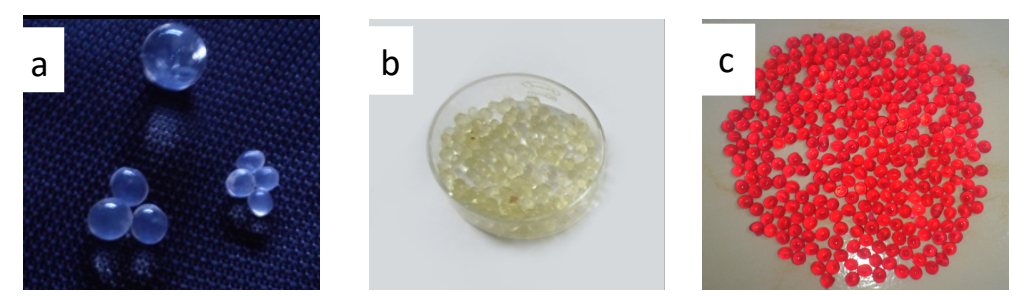

Fig.-1: Immobilized Trameteshirsuta Beads Various Diameter (a), Beads before (b) and after (c) experiment

\section{Preparation of Simulated Textile Effluent (STE)}

The simulated textile wastewater is prepared according to the procedure suggested elsewhere. ${ }^{19}$ The mixture of reactive dyes included Congo Red (CR), Reactive Red 111 (RR111) and Reactive Red 251 (RR251) in simulated wastewater. This dye is normally used for dyeing cotton and woollen fabric. Starch solution is hydrolyzed by mixing with $4 \%$ of sodium hydroxide at $80^{\circ} \mathrm{C}$ for $2 \mathrm{~h}$ and leaving it at room temperature overnight. The STE contains trace metal solution in $\mathrm{g} / \mathrm{l}: \mathrm{CaCl}_{2}: 5 \mathrm{~g} / \mathrm{l}, \mathrm{MgSO}_{4}$ $.7 \mathrm{H}_{2} \mathrm{O}: 5, \mathrm{FeCl}_{2} .4 \mathrm{H}_{2} \mathrm{O}: 6, \mathrm{COCl}_{2}: 0.88, \mathrm{H}_{3} \mathrm{BO}_{3}: 0.1, \mathrm{ZnSO}_{4} .7 \mathrm{H}_{2} \mathrm{O}: 0.1, \mathrm{CuSO}_{4}: 0.05, \mathrm{NiSO}_{4}: 1$ $\mathrm{MnCl}_{2}: 5,\left(\mathrm{NH}_{4}\right)_{6} \mathrm{Mo}_{7} \mathrm{O}_{24} .4 \mathrm{H}_{2} \mathrm{O}: 0.64$ and $\mathrm{CaCl}_{2} .2 \mathrm{H}_{2} \mathrm{O}: 5$.

\section{Continuous Degradation Studies by Trametes hirsuta}

Biodegradation studies of STE using Trametes hirsuta in a packed bed reactor are performed. The reactor is made up of perplex cylindrical column with $2.5 \mathrm{~cm}$ diameter and $10 \mathrm{~cm}$ height containing a working volume of $64 \mathrm{ml}$. Initially the column is filled with immobilized $\mathrm{Na}$ alginate biomass beads on to the required bed height. Laccase production medium with known concentration of STE is passed to the packed bed reactor at the bottom using peristaltic pump at particular flow rate and the experiments are carried out at room temperature. The experiments are conducted by changing the liquid flow rates, diameter of the beads and initial concentration of effluent. Different ranges of variables used in the continuous study are listed in Table-1.

Table-1: Range of Variables used in the Continuous Study

\begin{tabular}{c|c|c}
\hline S. No. & Variables & Range \\
\hline 1 & Particle diameter $(\mathrm{cm})$ & $0.2-0.8$ \\
\hline 2 & Flow rate $\left(\mathrm{m}^{3} / \mathrm{s}\right)$ & $0.026-0.408$ \\
\hline 3 & Initial STE concentration $(\mathrm{mg} / \mathrm{l}$ of COD) & $775-3100$ \\
\hline
\end{tabular}




\section{Determination of Mass Transfer Co-efficient}

Model with enzyme kinetics: Material balance combined with flux, represented as mass transfer coefficients, external surface for mass transfer and concentration gradient were used to estimate the mass transfer coefficients ${ }^{20,21,22}$ i.e.

$$
k_{f} a_{m}=\frac{N_{\text {ave }}}{V_{e f f} \Delta C}
$$

Where $\mathrm{N}_{\text {ave }}=\left(\mathrm{C}_{1}-\mathrm{C}_{2}\right) \mathrm{Q}, \mathrm{V}_{\text {eff }}$ the effective volume of the reactor and $\Delta C$ the overall concentration difference $\left(\mathrm{C}_{0}-\mathrm{C}_{\mathrm{s}}\right)$.

$$
a_{m}=\left[\frac{(1-\varepsilon) \pi d_{p}^{2}}{\pi d_{p}^{3} / 6}\right]=\frac{6(1-\varepsilon)}{d_{p}}
$$

The supply rate of dye by mass transfer is equal to the dye consumed at the catalyst interface under steady-state conditions.. Applying Michaelis-Menten kinetics at the surface the reaction rate will be

$$
k_{f} a_{m}\left(C_{0}-C_{s}\right)=\frac{v_{\max } C_{s}}{K_{m}+C_{s}}
$$

Damkohler number $\left(\mathrm{N}_{\mathrm{Da}}\right)$, Which is the ratio of the maximum rate of reaction to the maximum rate of mass transfer i.e.

$$
N_{D a}=\frac{v_{\max }}{k_{f} a_{m} C_{0}}
$$

Mass transfer model with first order kinetics

$$
\begin{array}{r}
\ln \left(\frac{C_{t}}{C_{0}}\right)=\ln (1-X)=-k_{p s} \tau \\
\boldsymbol{k}_{p s}=\frac{\boldsymbol{k} \boldsymbol{k}_{f} \boldsymbol{a}_{\boldsymbol{m}}}{\boldsymbol{k}+\boldsymbol{k}_{\boldsymbol{f}}}
\end{array}
$$

Where $X$ is the fractional substrate conversion $\left(1-\left(C_{t} / C_{0}\right)\right)$ and $\tau$ the space time $(V / Q)$. The pseudo first order rate constant $\left(k_{p s}\right)$, used to elucidate the film diffusion model

$$
k_{f}=A G^{n}
$$

Where the parameter $\mathrm{A}$ is defined as,

$$
A=\left(\frac{K}{\rho}\right)\left(\frac{\mu}{\rho D_{f}}\right)^{-2 / 3}\left(\frac{d_{p}}{\mu}\right)^{n-1}
$$

Substituting Eq. (10) into Eq. (8) and rearranging to yield,

$$
\left(\frac{1}{k_{p s}}\right)=\left(\frac{1}{A a_{m}}\right)\left(\frac{1}{G^{n}}\right)+\left(\frac{1}{k a_{m}}\right)
$$

A plot of the estimated values of $\left(1 / k_{p s}\right)$ versus $\left(1 / G^{n}\right)$, yields a straight line of slope $\left(1 / A a_{m}\right)$ and an intercept $\left(1 / k a_{m}\right)$.

\section{RESULTS AND DISCUSSION}

The formation of surface film on the immobilized $\mathrm{Na}$ alginate beads in a co-current packed bed reactor with up flow mode of operation relatively reduces the observed rate of the reaction. This external film diffusion effect depends on the STE solution's mass flow rate. The mass transfer coefficients for STE was calculated for different conditions of column operation, based on the experimental results. The results of mass transfer were then combined with the biochemical reaction and a quantitative model of mass transfer was developed in terms of the factor Colburn ' $j_{D}$.' The residual STE concentrations are determined by COD of the effluent. 
RASĀYAN J. Chem.

Vol. 14 | No. 1 |254-260| January - March | 2021

Table-2: Experimental and Calculated Values of the Parameter $A$ used in Eq. (8)

\begin{tabular}{c|c|c|c|c}
\hline S. No. & $\begin{array}{c}\text { Diameter of } \\
\text { the Bead }(\mathrm{cm})\end{array}$ & $\mathrm{n}$ & $\begin{array}{c}\mathrm{A}\left(\mathrm{x} 10^{4} \mathrm{~g}^{0.72} \mathrm{~cm}^{-2.44} \mathrm{~s}^{0.28}\right) \\
\text { STE (Experimental using Eq.8) }\end{array}$ & $\begin{array}{c}\mathrm{A}\left(\mathrm{x} 10^{4} \mathrm{~g}^{0.72} \mathrm{~cm}^{-2.44} \mathrm{~s}^{0.28}\right) \\
\text { STE (Calculated from Fig.-3) }\end{array}$ \\
\hline 1 & 0.2 & 0.72 & 2.28 & 2.22 \\
\hline 2 & 0.5 & 0.72 & 1.66 & 1.92 \\
\hline 3 & 0.8 & 0.72 & 0.983 & 0.999 \\
\hline
\end{tabular}

The decolorization of STE by immobilized T. hirsuta was found to fits well with the MichaelisMenten kinetics. The Damkohler number estimated for the immobilized T. hirsuta bead size is found to be greater than 1. Since $\mathrm{N}_{\mathrm{Da}}>>1$, The resistance to mass transfer is large or, in other words, the rate of mass transfer is much lower than the rate of reaction with the overall rate of reaction being a first order with mass transfer as the process of limitation.

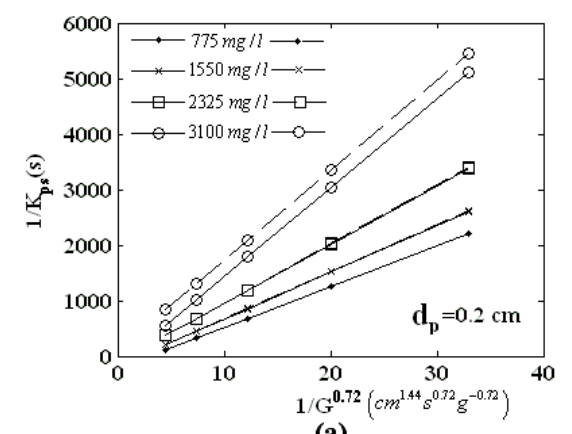

(a)
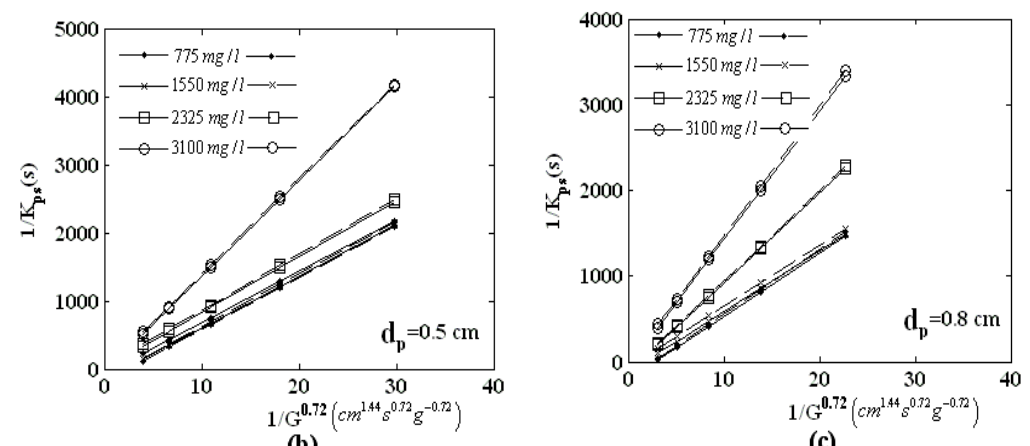

(c)

Fig.-2. Plot of $\left(1 / k_{p s}\right) V s\left(1 / G^{0.72}\right)$ for the Degradation of STE with Different Particle Size

The experimental data of $Q_{\text {and }} k_{p s}$, and the calculated values of ${ }^{1 / k_{p s}}, R \mathrm{e}, \mathrm{g}$, and ${ }^{1 / G^{n}}(0<n<1)$ are compared for the degradation STE by immobilized T. hirsuta for $d_{p}=0.2,0.5,0.8 \mathrm{~cm}$. The Eq. (9) is analyzed for different values of ' $n$ ' ranging from 0.1 to 1.0. From the values of slope ( $\left(1 / \mathrm{Aa}_{\mathrm{m}}\right)$ obtained for different experimental conditions, using Eq. (8) and Eq. (10), the estimated value of external surface area for mass transfer ' $a_{m}$ ' matches well with actual ' $a_{m}$ ' (obtained using Eq. (2.0)), for an assumed value of $n=0.72$. The same trial and error procedure have been repeated for all the ' $n$ ' values (0.1-1.0) and however except for $\mathrm{n}=0.72$, the calculated value of ' $\mathrm{a}_{\mathrm{m}}$ ' does not match well with the actual ' $a_{m}$ ' values. The value of ' $n$ ' that yields a value of ' $a_{m}$ ' matching with the experimental ' $\mathrm{a}_{\mathrm{m}}$ ' provides the correct external mass transfer correlation.

Figure-2 shows the plot of $1 / \mathrm{K}_{\mathrm{ps}}$ versus $1 / \mathrm{G}^{\mathrm{n}}$ for the degradation of STE and for an assumed value of $\mathrm{n}$ $=0.72$. The estimated value of the intrinsic first-order rate constant, ' $k$ ' from the intercept $\left(1 / \mathrm{ka}_{\mathrm{m}}\right)$ is $1.516 \mathrm{~cm} \mathrm{~s}^{-1}$ for STE. The surface area of mass transfer is found to increase with a decrease in the particle diameter. The predicted ' $\mathrm{am}_{\mathrm{m}}$ ' values are found to be $21.18,16.12 \& 3.44 \mathrm{~cm}^{2} \mathrm{~cm}^{-3}$ for STE, which are in good agreement with the actual value of ' $\mathrm{a}_{\mathrm{m}}$ ' according to Eq. (2) as 12.6, 11.0 and 2.47 $\mathrm{cm}^{2} \mathrm{~cm}^{-3}$ for three different particle sizes, viz. $0.2,0.5$ and $0.8 \mathrm{~cm}$ and for an assumed values of $\mathrm{n}=$ 0.72 . The estimated values of ' $\mathrm{K}$ ' in Eq. (10) are found to be $1.98,1.35 \& 1.22$ for STE for the three different particle sizes, viz. $0.2 \mathrm{~cm}, 0.5 \mathrm{~cm}$ and $0.8 \mathrm{~cm}$. The differences in the value of constant ' $\mathrm{K}$ ' for STE are due to the different composition and characteristics of the effluents.

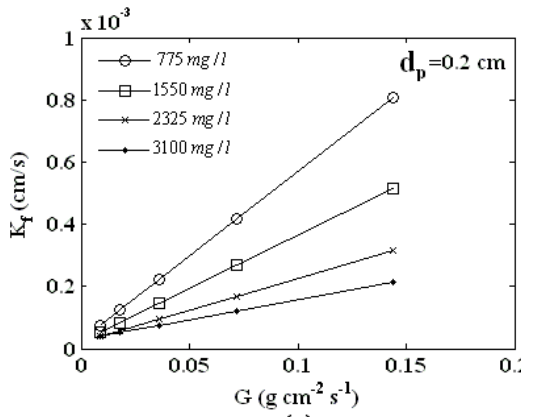

(a)

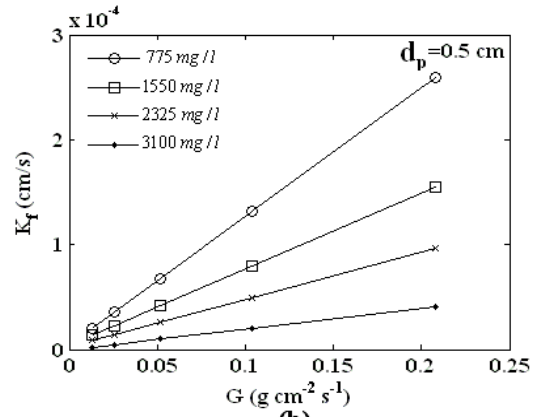

(b)

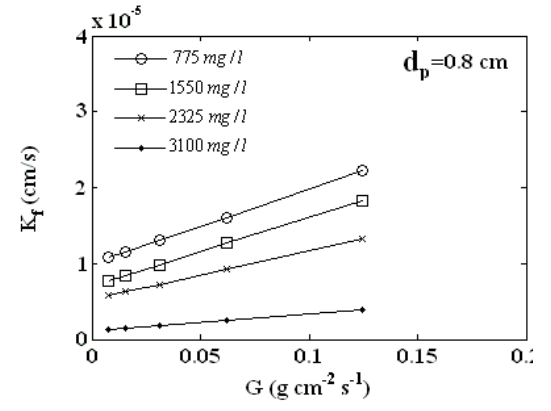

(c)

Fig.-3: Effect of Mass Flow Rate on External Mass Transfer Coefficient using Different Particle Diameters for the Degradation of STE. 
Figure-3 shows the plot between mass transfer coefficient and mass flow rate for STE using immobilized $T$. hirsuta beads in logarithmic coordinates. The values of $A$ and $n$ thus obtained from Fig.4, are compared with that calculated according to Eq. (8) and are given in Table-2. The good agreement of these values confirms the applicability for this study of packed bed reactors to STE degradation of the present mass transfer model. The result indicates that the influent flow rate controls degradation of the STE. When the input flow rate increases, the total input of the contaminants per minute increases, resulting in a reduction of the surface film thereby increasing the rate of mass transfer. The estimated coefficients of mass transfer are found to rise with reduction in particle diameter. In the case of smaller particles the higher mass transfer coefficient is due to the increased surface area.

Table-3: Correlations in terms of Modified Reynolds Number

\begin{tabular}{c|c|c|c}
\hline \multirow{2}{*}{ Effluent } & \multicolumn{3}{|c}{ Correlation } \\
\cline { 2 - 4 } & \multicolumn{3}{|c}{ Diameter of the immobilized beads $\left(\mathrm{d}_{\mathrm{p}}\right)(\mathrm{cm})$} \\
\cline { 2 - 4 } & $\mathrm{d}_{\mathrm{p}}=0.2 \mathrm{~cm}$ & $\mathrm{~d}_{\mathrm{p}}=0.5 \mathrm{~cm}$ & $\mathrm{~d}_{\mathrm{p}}=0.8 \mathrm{~cm}$ \\
\hline STE & $j_{D}=1.98\left(R \mathrm{e}^{\prime}\right)^{-0.28}$ & $j_{D}=1.35\left(R \mathrm{e}^{\prime}\right)^{-0.28}$ & $j_{D}=1.22\left(R \mathrm{e}^{\prime}\right)^{-0.28}$ \\
\hline
\end{tabular}

Figure-4 shows the effect of initial dye concentration on external mass transfer coefficient for the decolorization of STE by immobilized T. hirsuta at particular flow rates. It is also observed from the analysis of the present data that the value of the constant K in Eq. (9) varies with bed voidage. Since the mass transfer rates observed that are directly proportional to the particle size, the effect of bed voiding in the form of spherical particles is $\varepsilon$ or $(1-\varepsilon)$ have to be considered instead of the particle diameter $d_{p}$.

The general form of the correlation in terms of modified Reynolds number is represented as:

$$
j_{D}=K\left(R e^{\prime}\right)^{n-1}
$$

Where $\mathrm{Re}^{\prime}=R \mathrm{e} / 1-\varepsilon$ and the correlations in terms of modified Reynolds number for the decolorization of STE using immobilized $T$.hirsutaare given in Table-3 with a minimum error of $<1 \%$. For steady-state mass transfer combined with biochemical reaction in a packed bed reactor, a mass transfer correlation (Eq. (10)) is adopted, which represents the present experimental data accurately. This correlation would be useful for the design and development of up flow packed bed reactor for the continuous decolorization of dyes using immobilized T. hirsuta beads. This model would be useful to quantify the external film diffusion effects for the continuous decolorization of dyes in packed bed reactor.

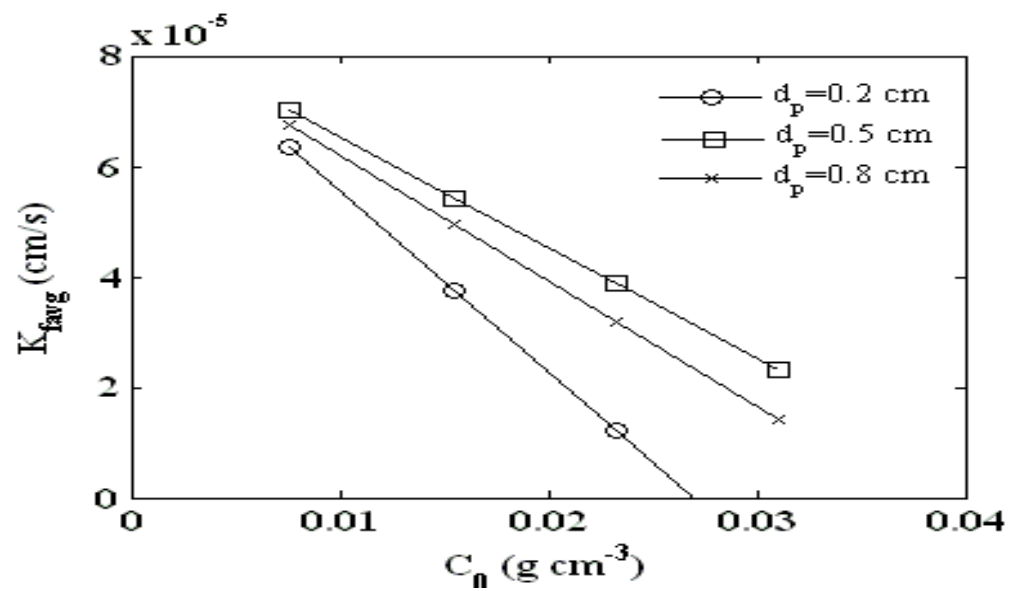

Fig.-4: Effect of Initial Concentration on the External Mass Transfer Coefficient for the Decolorization of RB5 and Degradation of STE.

\section{CONCLUSION}

In this study, biodegradation of STE was conducted with immobilized Na- alginate beads in the presence of T. hirsuta in packed bed bioreactor. The combined effect of external mass transfer with biochemical reaction on STE was analyzed. The mass transfer coefficients for the STE were found to increase with increasing mass flow rates for the range covered in the present study. In terms of the Chilton - Colburn ' $j_{D}$ ' factor and Reynolds number, i.e., $j_{D}=K\left(R^{\prime}\right)^{n-1}$, the proposed mass transfer model would be useful for the design and development of immobilized packed bed reactors for the continuous treatment of STE. However, the applicability of this model must be verified for the TEXTILE EFFLUENT IN PACKED BED REACTOR 
treatment of both viscous and non-Newtonian effluents. The specific conclusions drawn from the study are

as

follows: With a decrease in particle diameter the surface area of the mass transfer is found to increase, With rising flow rates for the range covered in the present study, the mass transfer coefficients are fou nd to increase. The calculated mass transfer coefficients for the dyes studied are also found to increase with a decrease in the diameter of the beads. This research is providing important information for future conversion scale up studies.

\begin{tabular}{|c|c|c|c|}
\hline \multicolumn{4}{|l|}{ Nomenclature } \\
\hline & $\mathrm{a}_{\mathrm{m}}$ & - & External surface area for mass transfer $\left(\mathrm{cm}^{2} \mathrm{~cm}^{-3}\right)$ \\
\hline & $C_{s}$ & - & Substrate concentration at the surface of immobilized cell $\left(\mathrm{g} \mathrm{cm}^{-3}\right)$ \\
\hline & $C_{0}$ & - & Initial substrate concentration $\left(\mathrm{g} \mathrm{cm}^{-3}\right)$ \\
\hline & $d_{c}$ & - & Column diameter $(\mathrm{cm})$ \\
\hline & $d_{p}$ & - & Particle diameter $(\mathrm{cm})$ \\
\hline & $D_{f}$ & - & Diffusivity of the substrate $\left(\mathrm{cm}^{2} \mathrm{~s}^{-1}\right)$ \\
\hline & $G$ & - & Mass flux based on superficial velocity $\left(\mathrm{g} \mathrm{cm}^{-2} \mathrm{~s}^{-1}\right)$ \\
\hline & $H$ & - & Bed height $(\mathrm{cm})$ \\
\hline & $j_{D}$ & - & Dimensionless group \\
\hline & $k$ & - & Intrinsic first order rate constant $\left(\mathrm{cm} \mathrm{s}^{-1}\right)$ \\
\hline & $k_{f}$ & - & Mass transfer coefficient $\left(\mathrm{cm} \mathrm{s}^{-1}\right)$ \\
\hline & $k_{p s}$ & - & Pseudo first order constant $\left(\mathrm{s}^{-1}\right)$ \\
\hline & $K$ & - & Constant \\
\hline & $K_{m}$ & - & MichaleisMentenconstant $\left(\mathrm{g} \mathrm{cm}^{-3}\right)$ \\
\hline & $n$ & - & Exponent \\
\hline & $N_{a v e}$ & - & Mass transfer rate $\left(\mathrm{g} \mathrm{s}^{-1}\right)$ \\
\hline & $N_{D a}$ & - & Damkohler number \\
\hline & $Q$ & - & Volumetric flow rate $\left(\mathrm{cm}^{3} \mathrm{~s}^{-1}\right)$ \\
\hline & $r_{r}$ & - & Reaction rate $\left(\mathrm{g} \mathrm{cm}^{-3} \mathrm{~s}^{-1}\right)$ \\
\hline & $R e$ & - & Reynolds number $\left(d_{p} G / \mu\right)$ \\
\hline & $R e^{\prime}$ & - & Modified Reynolds number $\left[d_{p} G / \mu(1-\varepsilon)\right]$ \\
\hline & $S c$ & - & Schmidt number $\left(\mu / \rho D_{f}\right)$ \\
\hline & Sh & - & Sherwood number $\left(k_{f} d_{p} / D_{f}\right)$ \\
\hline & $t$ & - & Time (s) \\
\hline & $X$ & - & Fractional substrate conversion \\
\hline & $\varepsilon$ & - & Bed voidage \\
\hline & $\mu$ & - & Fluid viscosity $\left(\mathrm{g} \mathrm{cm}^{-1} \mathrm{~s}^{-1}\right)$ \\
\hline & $\rho$ & - & Fluid density $\left(\mathrm{g} \mathrm{cm}^{-3}\right)$ \\
\hline & $\mu_{\max }$ & - & Maximum specific growth rate $\left(\mathrm{g} \mathrm{cm}^{-3} \mathrm{~s}^{-1}\right)$ \\
\hline & $\mu$ & - & Specific growth rate $\left(\mathrm{g} \mathrm{cm}^{-3} \mathrm{~s}^{-1}\right)$ \\
\hline
\end{tabular}

\section{REFERENCES}

1. N. D. Lourenço, J. M. Novais and H. M. Pinheiro, Biotechnology Letter, 28, 733(2006), DOI: $10.1007 / \mathrm{s} 10529-006-9051-5$

2. D. A. Yaseen and M. Scholz, International Journal of Environmental Science and Technology, 16, 1193(2019), DOI:10.1007/s13762-018-2130-z

3. S. Rengadurai, M.G. Devanesan, P. Elavarasan and S. B. Riswanali, International Journal For Innovative Research In Multidisciplinary Field, 14, 26(2020), DOI:10.2015/IJIRMF.2455.0620/IBCFT.03.2020

4. C. Zaharia, D. Suteu, D. Bilba, A. Muresan, R. Muresan and A. Popescu, Environmental Engineering and Management Journal, 8 (6), 1359 (2009), DOI:10.30638/eemj.2009.199 
5. S. Rengadurai, B. Preetha, American International Journal of Research in Sciences, Technology, Engineering and Mathematics, Spl. Issue, 157(2019).

6. U. D. Patel and S. Sumathi, Journal of Hazardous Materials, 156 (1-3), 308(2008), DOI:10.1016/j.jhazmat.2007.12.021

7. D. Rawat, V. Mishra and R.S. Sharma, Chemosphere, 155, 591(2016), DOI:10.1016/j.chemosphere.2016.04.068

8. S. Mani and R.N. Bharagava, Reviews of Environmental Contamination and Toxicology, 237, 71 (2016), DOI:10.1007/978-3-319-23573-8_4

9. F. Spina, C. Junghanns, I. Donelli, R. Nair, P. Demarche, A. Romagnolo, G. Freddi, S.N. Agathos and G. C. Varese, Preparative Biochemistry \& Biotechnology, 46, 639(2016), DOI: $10.1080 / 10826068.2015 .1128445$

10. A. M. Patel, V. M. Patel, J. Pandya, U. B. Trivedi and K. C. Patel, Water Conservation Science and Engineering, 2, 85(2017), DOI:10.1007/s41101-017-0028-0

11. V. Kokol, A. Doliska, I. Eichlerova, P. Baldrian and F. Nerud, Enzyme and Microbial Technology, 40 (7), 1673(2007), DOI:10.1016/j.enzmictec.2006.08.015

12. H. Zouari-Mechichi, T. Mechichi, A. Dhouib, S. Sayadi, A. T. Martinez and M.J. Martinez,Enzyme and Microbial Technology, 39 (1), 141(2006), DOI:10.1016/j.enzmictec.2005.11.027

13. P. Pallavi, P. King and Y. Prasanna Kumar, Rasayan Journal of Chemistry, 11 (1), 203(2018), DOI:10.7324/RJC.2018.1111971

14. X. Quan, H. Shi, Y. Zhang, J. Wang and Y. Qian, Separation and Purification Technology, 34 (13), 97 (2004), DOI:10.1016/S1383-5866(03)00181-3

15. A. Banerjee and A. K. Ghoshal, Journal of Environmental Chemical Engineering, 5 (2), 1696 (2017), DOI:10.1016/j.jece.2017.03.008

16. A. Y. Dursun and Z. Aksu, Process Biochemistry, 35 (6), 615 (2000),DOI:10.1016/S00329592(99)00110-7

17. D.O.Cooney, AIChE Journal, 37 (8), 1270 (1991), DOI:10.1002/aic.690370820

18. H. Revathi, A. Xavier, M. Dinesh Kumar, T.Saranya, A. Kaviyarasu and T.Murugan, Rasayan Journal of Chemistry, 12 (2), 719 (2019), DOI:10.31788/RJC.2019.1225094

19. C. O’Neill, F. R. Hawkes, D. L. Hawkes, S. Estves and S. J. Wilcox, Water Research, 34(8), 2355 (2000). DOI:10.1016/S0043-1354(99)00395-4

20. C.Y. Hoon and L.C. Tin, in Proceedings of the $1^{\text {st }}$ International Conference on Natural Resources Engineering and Technology, Malaysia, 500-509, (2006).

21. O. Tepe and A.Y. Dursun, Journal of Hazardous Materials, 151(1), 9(2008), DOI:10.1016/j.jhazmat.2007.05.049

22. S. R. Geed, M. K. Kureel, S. Prasad, R. S. Singh and B. N. Rai, Journal of Environmental Chemical Engineering,6 (2), 3444 (2018), DOI:10.1016/j.jece.2018.05.025

[RJC-6087/2020] 